This item was submitted to Loughborough's Research Repository by the author.

Items in Figshare are protected by copyright, with all rights reserved, unless otherwise indicated.

\title{
Chemical incorporation of copper into indium selenide thin-films for processing of CulnSe2 solar cells
}

PLEASE CITE THE PUBLISHED VERSION

http://onlinelibrary.wiley.com/journal/10.1002/(ISSN)1099-159X

\section{VERSION}

SMUR (Submitted Manuscript Under Review)

\section{LICENCE}

CC BY-NC-ND 4.0

\section{REPOSITORY RECORD}

Hibberd, Christopher J., K.E. Ernits, M. Kaelin, U. Muller, and A.N. Tiwari. 2019. "Chemical Incorporation of Copper into Indium Selenide Thin-films for Processing of Cuinse2 Solar Cells". figshare. https://hdl.handle.net/2134/4926. 
This item was submitted to Loughborough's Institutional Repository (https://dspace.lboro.ac.uk/) by the author and is made available under the following Creative Commons Licence conditions.

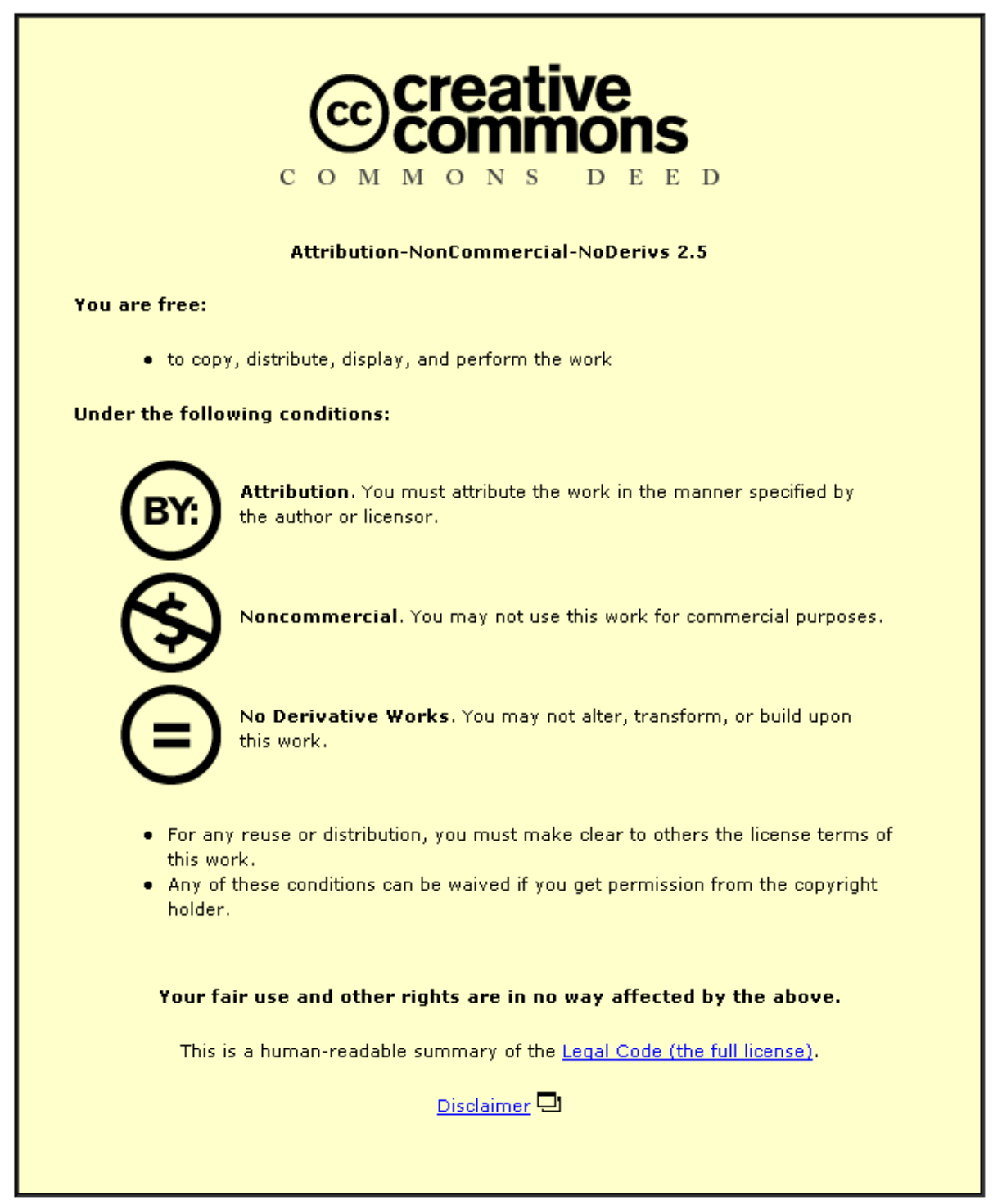

For the full text of this licence, please go to: http://creativecommons.org/licenses/by-nc-nd/2.5/ 


\title{
Chemical incorporation of copper into indium selenide thin-films for processing of CulnSe $\mathrm{C}_{2}$ solar cells
}

\author{
C. J. Hibberd ${ }^{1 *}$, K. Ernits ${ }^{2}$, M. Kaelin ${ }^{2}$, U. Müller ${ }^{3}$, A. N. Tiwari ${ }^{1,2}$ \\ 1)Centre for Renewable Energy Systems Technology, Holywell Park GX Area, Department for Electronic and \\ Electrical Engineering, Loughborough University, Leicestershire, LE11 3TU, UK \\ 2) Thin Film Physics Group, Laboratory for Solid State Physics, ETH Zurich, Technopark, 8005 Zurich, \\ Switzerland \\ 3)EMPA - Materials Science and Technology, EMPA Duebendorf, Abt.125, Laboratory for Nanoscale Materials \\ Science, Ueberlandstrasse 129, CH-8600 Duebendorf, Switzerland \\ *Corresponding author: C.J.Hibberd@lboro.ac.uk
}

\section{Abstract}

A chemical method of incorporating copper into indium selenide thin-films has been investigated, with the goal of creating a precursor structure for conversion into $\mathrm{CuInSe}_{2}$ layers suitable for solar cell processing. The precursor and converted layers have been investigated with scanning electron microscopy, x-ray diffraction, Raman spectroscopy and x-ray photoelectron spectroscopy. From these measurements, the incorporation of copper into the indium selenide layers is concluded to proceed by an ion-exchange reaction. This reaction results in the formation of a precursor layer with a graded compositional depth-profile containing the crystalline phases $\operatorname{In}_{2} \mathrm{Se}_{3}$ and $\mathrm{Cu}_{2-\mathrm{x}} \mathrm{Se}$. Selenization of the precursor layer homogenises the composition and forms chalcopyrite $\mathrm{CuInSe}_{2}$. These CuInSe $\mathrm{S}_{2}$ layers exhibit a dense microstructure with rough surface morphology, which is ascribed to a non-optimal selenization process. Solar cells with the structure $\mathrm{ZnO}: \mathrm{Al} / \mathrm{i}-\mathrm{ZnO} / \mathrm{CdS} / \mathrm{CuInSe} / \mathrm{Mo} / \mathrm{Glass}$ have been processed from the selenized layers and have exhibited efficiencies of up to $4 \%$ under simulated AM1.5 illumination.

\section{Introduction}

$\mathrm{CuInSe}_{2}$ (CIS) and its alloys with Ga and S are suitable materials for absorber layers in high-efficiency thin-film solar cells. The highest efficiency cells reported to date $(19.5 \%)$ were made from copper-poor $\mathrm{Cu}$ (In, Ga) $\mathrm{Se}_{2}$ (CIGS) deposited by the threestage process [1]. In this vacuum co-evaporation process an (In, $\mathrm{Ga})_{2} \mathrm{Se}_{3}$ layer is deposited and then converted into a $\mathrm{Cu}$-rich $\mathrm{CIGS}$ layer by exposure to $\mathrm{Cu}$ and $\mathrm{Se}$ fluxes at high temperature before further evaporation of In, Ga and Se turn the layer $\mathrm{Cu}$-poor [2].

A simpler approach might be advantageous for large-scale production of CIGS solar cells and so methods have been investigated that terminate the second stage before the CIGS layer composition turns Cu-rich [3-6]. In methods where the material deposition is performed at relatively low temperatures, a high temperature anneal is employed to react the resulting bilayer structures [7-10]. Se vapour is often supplied during this annealing stage, in which case it may be referred to as selenization.

Substrate temperature during the material deposition has been shown to have a strong effect on the efficiency of the solar cells produced using two-stage deposition methods $[5,10]$. Sequential deposition of $\mathrm{In}-\mathrm{Se}$ and $\mathrm{Cu}-\mathrm{Se}$ at room temperature was reported to result in delamination of the precursor during annealing for CIGS layers, however deposition at $100^{\circ} \mathrm{C}$ was already sufficient to give cells of $13.3 \%$ efficiency following selenization at over $500^{\circ} \mathrm{C}$. For the depositions performed at $100^{\circ} \mathrm{C}$ substrate temperature the $\mathrm{In}-\mathrm{Se}$ and $\mathrm{Cu}$-Se layers were found to have begun to inter-diffuse, whereas room temperature deposition produced a sharp interface 
between the layers. Higher deposition temperatures were reported to lead to improved efficiencies, up to $15.5 \%$ at $350^{\circ} \mathrm{C}$ (with selenization at $>500^{\circ} \mathrm{C}$ ) and $16.6 \%$ at $550^{\circ} \mathrm{C}$ (without selenization) [5, 10]. For Ga-free CIS devices, when $\mathrm{Cu}$ and $\mathrm{Se}$ were supplied to an indium selenide precursor layer at $200^{\circ} \mathrm{C}$ solar cells of $13.7 \%$ were reported [8]. These results show that even at low temperatures $\mathrm{Cu}-\mathrm{Se}$ supply to $\operatorname{In}(\mathrm{Ga})$-Se precursors can result in $>10 \%$ efficiency CIS-based solar cells, so long as a high temperature selenization treatment is provided.

All of the above-mentioned methods utilized vacuum evaporation, however the deposition temperatures employed in some cases are accessible to chemical methods, such as ion-exchange processes. Ion-exchange reactions, where ions in a thin film exchange places with ions in a solution or gas, are attractive from a technological point of view: they require only simple, low-cost equipment, can proceed at high rates and require relatively low temperatures. In the case of solution-based techniques, since the reaction only occurs at the substrates the baths can used for an extended period and be easily regenerated. Cation-exchange reactions have been used to create graded structures for thin-film solar cells, including $\mathrm{Cu}_{2} \mathrm{~S}-\mathrm{CdS}$ [11], $\mathrm{Cu}_{\mathrm{x}} \mathrm{Te}-\mathrm{CdTe}$ [12] and $\left(\mathrm{Cu}_{2-\mathrm{x}}, \mathrm{Cd}_{\mathrm{x}}\right)(\mathrm{In}, \mathrm{Ga}) \mathrm{Se}_{2}-\mathrm{Cu}(\mathrm{In}, \mathrm{Ga}) \mathrm{Se}$ [13]. In addition to creating graded structures, ion-exchange reactions can be used to create ternary compounds. For example $\mathrm{CuInS}_{2}$ has been produced by a low-temperature, gas-based anion-exchange reaction involving metal chloride layers adsorbed from solution [14]. $\mathrm{CuInS}_{2}$ has also been created in a solution-based cation-exchange reaction by first creating mixed $\mathrm{In}_{2} \mathrm{~S}_{3}-\mathrm{Cu}_{\mathrm{x}} \mathrm{S}$ nanorods from $\operatorname{In}_{2} \mathrm{~S}_{3}$ nanorods and then annealing them in $\mathrm{H}_{2} \mathrm{~S}$ to produce $\mathrm{CuInS}_{2}$ nanorods [15]. Ion-exchange reactions are found to proceed faster at areas where the crystal structure is disorganized, such as at grain boundaries and in materials with a crystal structure incorporating a high density of defects or vacancies. For polycrystalline substrate layers this leads to penetration of the new layer into the substrate layer and the creation of an interpenetrating structure [11]. Such interpenetrating layers formed by ion-exchange methods have similarities in structure to the inter-diffused layers formed by the sequential-deposition vacuum techniques described above.

In this work we used an ion-exchange reaction to incorporate $\mathrm{Cu}$ ions from aqueous solution into indium selenide thin-films. It is shown that these precursor layers have a graded composition $(\mathrm{Cu} / \mathrm{In}$ ratio) throughout the layer thickness that can be homogenised by annealing at high temperature in the presence of selenium vapour. This annealing leads to the formation of chalcopyrite $\mathrm{CuInSe} \mathrm{I}_{2}$ suitable for solar cell processing.

\section{Experiment}

The deposition of indium selenide layers has been demonstrated by several methods, including coevaporation of the elements [16], single-source evaporation of $\operatorname{In}_{2} \mathrm{Se}_{3}$ [8], sequential electrodeposition of the elements followed by annealing [17], simultaneous electrodeposition of the elements [18], modified chemical bath deposition [19] and spray pyrolysis [20]. In order to provide a high level of control and reproducibility in the indium selenide layers and hence allow the focus of this early-stage work to be maintained on the copper-incorporation process, co-evaporation of elemental indium and selenium was employed in the work reported here. However, any other process, e.g. a non-vacuum chemical deposition process, could equally be applied. The indium selenide layers were deposited onto $25 \mathrm{~cm}^{2}$ molybdenum-coated soda lime glass substrates by co-evaporation, due to the design of the sample holder an uncoated border of Mo was left around the edge of each substrate. 
Copper was incorporated into the indium selenide layers by suspending them in a covered, boiling, aqueous solution of $\mathrm{CuSO}_{4}(0.1 \mathrm{M})$ and acetic acid $(0.2 \mathrm{M})$. The acetic acid was required to prevent the formation of $\mathrm{Cu}(\mathrm{OH})_{2}$ in the solution due to hydrolysis of the $\mathrm{Cu}$ ions. After immersion, the precursor layers were rinsed thoroughly in deionised water and dried. Precursor layers were selenized with Se vapour in a two-temperature-zone quartz tube furnace under flowing $\mathrm{N}_{2}$. The two zones allowed the temperature of the Se source and hence the Se flux to be controlled separately from the temperature of the substrate. Typically the substrate temperature was ramped in stages to $575^{\circ} \mathrm{C}$ whilst the Se source was maintained at $400^{\circ} \mathrm{C}$. The selenization of some samples was interrupted at $250^{\circ} \mathrm{C}$ to investigate behaviour of the precursor layers during selenization.

To investigate the role of substrate-coating on $\mathrm{Cu}$ incorporation, indium selenide layers grown on $\mathrm{Mo} /$ glass, ITO/glass, $\mathrm{SnO}_{\mathrm{x}}: \mathrm{F} /$ glass were employed. Precursor and selenized layers were characterised by stylus profilometry, Scanning Electron Microscopy (SEM), Energy Dispersive X-ray analysis (EDX), X-Ray Diffraction (XRD), Raman spectroscopy and X-ray Photoelectron Spectroscopy (XPS). XRD measurements were made using $\mathrm{Cu} K \alpha$ radiation $(\lambda=0.15418 \mathrm{~nm})$, Raman spectroscopy measurements were made using a He-Ne laser $(\lambda=632.817 \mathrm{~nm})$ with $\mathrm{x} 10$ objective lens and XPS measurements used Al Ka radiation $(h v=1486.6 \mathrm{eV})$ with a $4 \mathrm{kV}$ Ar-ion sputter gun to enable depth profile measurements to be performed.

After completion of the absorber formation by selenization some layers were processed into solar cells. These layers were first etched in aqueous potassium cyanide solution $(10 \% \mathrm{w} / \mathrm{w})$ for 30 seconds before deposition of a CdS buffer layer by chemical bath deposition and a $\mathrm{ZnO}: \mathrm{Al} / \mathrm{i}-\mathrm{ZnO}$ bilayer-window by $\mathrm{RF}$ sputtering. I-V measurements were performed under $1 \mathrm{~kW} / \mathrm{m}^{2}$ simulated AM1.5 illumination.

\section{Results and Discussion}

Indium selenide precursor layers were immersed in the $\mathrm{CuSO}_{4}$ solution and removed after a time predetermined to give the desired $\mathrm{Cu}$ content. For the indium selenide layers used in this work, reaction times of around 1 hour were required to produce precursors with the correct $\mathrm{Cu} / \mathrm{In}$ ratio for $\mathrm{Cu}$-poor $\mathrm{CuInSe}$. No deposition was observed on the beaker containing the $\mathrm{CuSO}_{4}$ solution or on the PTFE sample holder and no precipitations were observed in the solution, even after heating and cooling. After the indium selenide precursor layers were removed from the $\mathrm{CuSO}_{4}$ solution it was observed that their appearance had turned lighter in colour and EDX measurements indicated that $\mathrm{Cu}$ had been incorporated into them. At this stage the composition of the precursor layers was non-uniform throughout the EDX electronbeam interaction volume, hence accurate, quantitative composition measurements could not be made with this technique. During immersion in the $\mathrm{CuSO}_{4}$ solution the Mo exposed around the border of the samples was removed from the substrate and some under-cutting of the edge of the indium selenide layers was observed. This is due to oxidation of the Mo into soluble molybdenum oxide. The appearance and composition of indium selenide layers deposited upon glass, fluorine-doped tin oxide and tin-doped indium oxide substrates remained unchanged after immersion in the $\mathrm{CuSO}_{4}$ solution. When a small piece of Mo coated glass was suspended in the $\mathrm{CuSO}_{4}$ solution, limited incorporation of $\mathrm{Cu}$ into indium selenide layers deposited on glass substrates was observed. It seems therefore that the presence of Mo activates the $\mathrm{Cu}$ incorporation into the precursor layers. Further investigation is necessary to explain the kinetics of $\mathrm{Cu}$ ion migration. 
XRD diffractograms are displayed in Figure 1 for precursor layers and selenized samples. All peaks in the diffractogram measured from the as deposited In-Se layer were indexed to hexagonal $\gamma-\operatorname{In}_{2} \mathrm{Se}_{3}$ (JCPDS files 40-1407 and 71-0250) and Mo (JCPDS file 42-1120). Following Cu-incorporation into an indium selenide layer, all but one of the $\mathrm{In}_{2} \mathrm{Se}_{3}$ peaks in the diffractogram weakened in intensity (relative to the Mo (110) peak). The exception is the peak at $27.6^{\circ}$, identified as the (006) peak. Two additional peaks are present in the diffractogram at this stage, one at $26.8^{\circ}$ and the other at $44.5^{\circ}$. These peaks are identified as the (111) and (220) peaks of fcc $\beta$ $\mathrm{Cu}_{2-x} \mathrm{Se}$ (JCPDS file 06-0680). The formation of copper selenide with $\mathrm{Cu}$ in its monovalent state requires that another species in the bath is oxidised. Since it was observed that the ion-exchange process did not proceed in the absence of Mo it is thought that the reduction of $\mathrm{Cu}^{2+}$ ions to $\mathrm{Cu}^{+}$is performed by oxidation of either Mo or a Mo oxide, however this has not been confirmed. For the sample selenized to $575^{\circ} \mathrm{C}$, all peaks in the diffractogram were indexed to $\alpha$-CuInSe 2 (JCPDS file 40 $1487)$ and Mo. The chalcopyrite peaks (101), (103), (211) and (105/213) are all observed. No significant preferred orientation is calculated for the diffractogram of this sample and there is no evidence of secondary oxide or binary-selenide phases. When the selenization process was interrupted at $250^{\circ} \mathrm{C}$, the measured diffractogram shows a very strong peak at $31.08^{\circ}$, identified as the (006) peak of hexagonal $\mathrm{CuSe}$ (JCPDS 49-1457). This indicates that that selenization reaction already begins below $250^{\circ} \mathrm{C}$ with the reaction of copper selenide and selenium vapour.

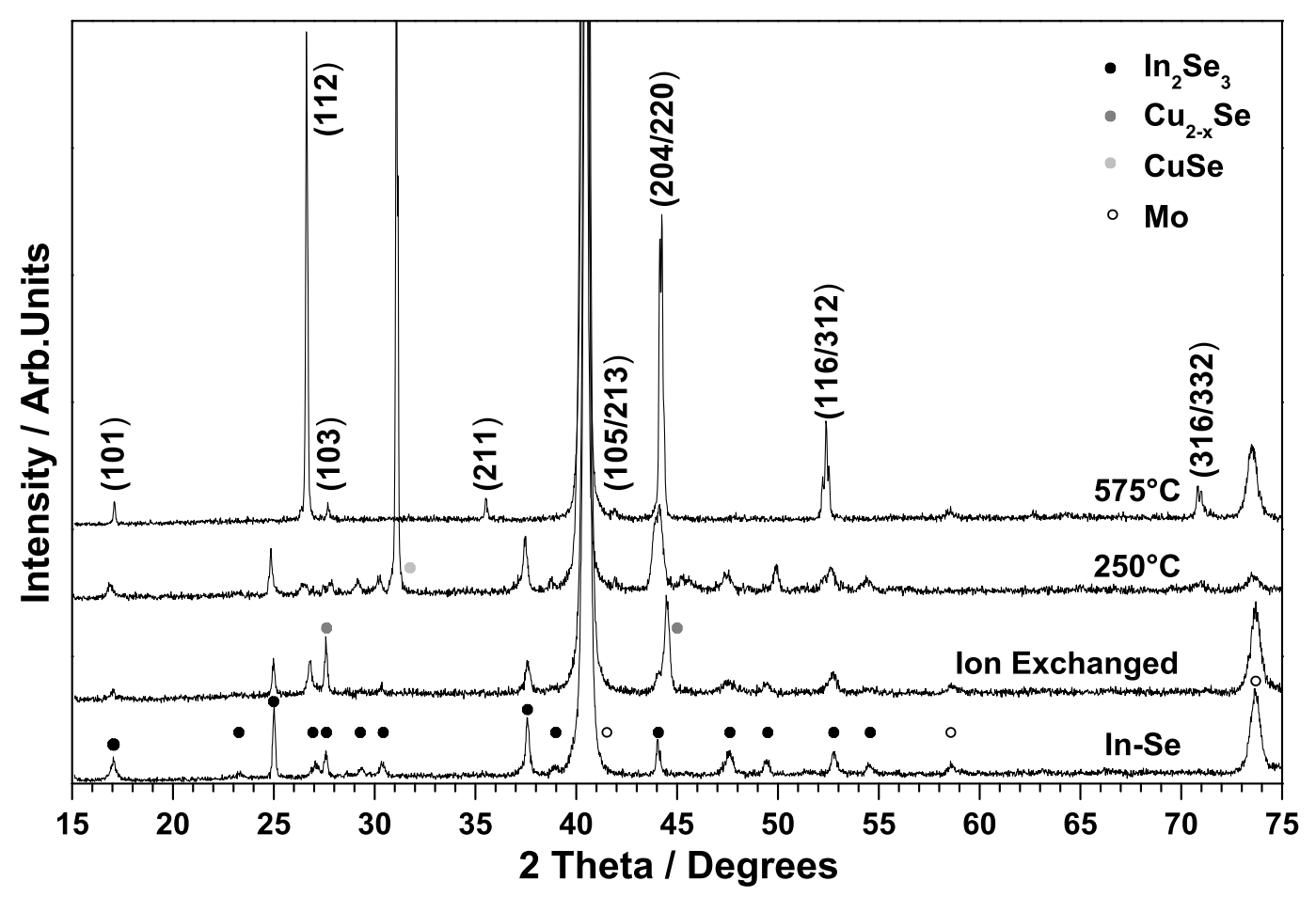

Figure 1: XRD Diffractograms for: an indium selenide layer; an indium selenide layer following $\mathrm{Cu}$-incorporation by ion-exchange; a precursor selenized at $250^{\circ} \mathrm{C}$ and a precursor selenized at $575^{\circ} \mathrm{C}$. All peaks in the diffractogram from the sample selenized at $575^{\circ} \mathrm{C}$ have been indexed to $\alpha$-CuInSe 2 and Mo.

Raman scattering measurements were performed for identification of the chemical phases in various layers. Raman spectra measured from samples at the same stages of 
processing as analysed by XRD are displayed in Figure 2. The Raman spectrum from the as-deposited indium selenide sample exhibits peaks at $151,205,228 \mathrm{~cm}^{-1}$, in good agreement with values reported for $\gamma-\operatorname{In}_{2} \mathrm{Se}_{3}$ [21]. The Raman spectrum of the indium selenide layer following $\mathrm{Cu}$-incorporation retains the $\gamma-\mathrm{In}_{2} \mathrm{Se}_{3}$ peak at $151 \mathrm{~cm}^{-1}$ and exhibits an additional peak at $260 \mathrm{~cm}^{-1}$, which is characteristic of copper selenide compounds [22]. This confirms that copper-selenium bonds are being formed during immersion of the indium selenide layers in the $\mathrm{CuSO}_{4}$ solution. In the Raman spectrum of the sample selenized to $575^{\circ} \mathrm{C}$ peaks are observed at 175,214 and $227 \mathrm{~cm}^{-1}$. The peak at $175 \mathrm{~cm}^{-1}$ is identified as the A1 peak of chalcopyrite CuInSe whilst both of the other two peaks are identified with B2 or E modes [23]. No copper selenide peaks are observed in this spectrum, however, a broad peak was present in the region $153-155 \mathrm{~cm}^{-1}$. The defect chalcopyrite compound $\mathrm{CuIn}_{3} \mathrm{Se}_{5}$ exhibits an A1 vibrational mode in this frequency range and is identified as a secondary phase in the selenized layers [24]. When the selenization was interrupted at $250^{\circ} \mathrm{C}$, no indium selenide peaks were observed in the Raman spectrum, however two new peaks were present at 263 and $275 \mathrm{~cm}^{-1}$. The peak at $263 \mathrm{~cm}^{-1}$ has been associated with CuSe [25], however no reports of an accompanying peak at $275 \mathrm{~cm}^{-1}$ could be found in the literature. The diffractogram measured from a sample with similarly interrupted selenization (displayed in Figure 1) indicates the presence of both CuSe and $\mathrm{In}_{2} \mathrm{Se}_{3}$ phases, therefore the absence of the indium selenide peaks in the Raman spectrum is attributed to a phase separation through the depth of the layer, leading to the Raman signal being generated solely within the copper selenide surface layer.

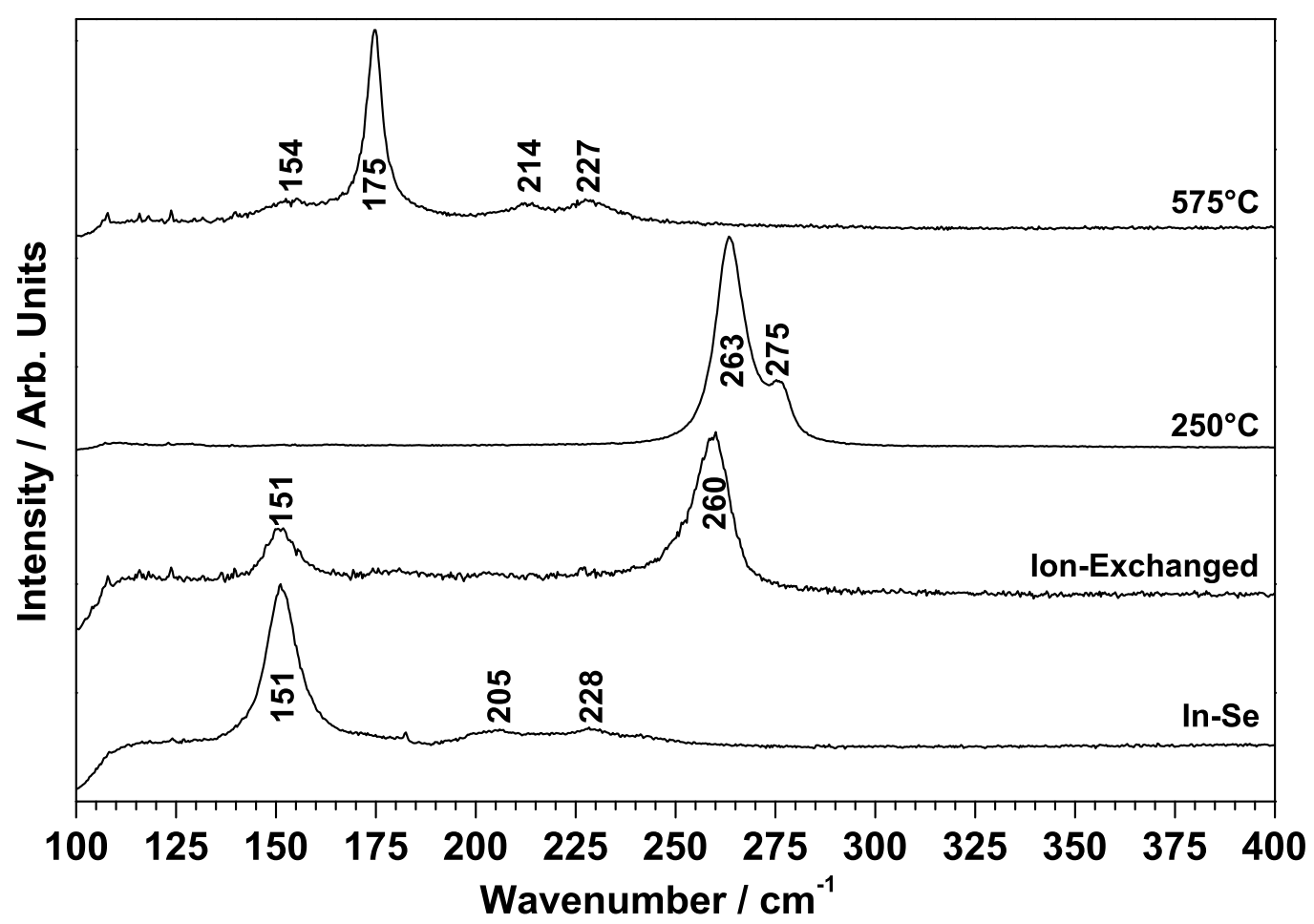

Figure 2: Raman spectra for: an indium selenide layer; an indium selenide layer following $\mathrm{Cu}$-incorporation by ion-exchange; a precursor selenized at $250^{\circ} \mathrm{C}$ and a precursor selenized at $575^{\circ} \mathrm{C}$. The Raman spectrum for the sample selenized at $575^{\circ} \mathrm{C}$ contains three peaks characteristic of $\mathrm{CuInSe}_{2}$ and a broad peak around $154 \mathrm{~cm}^{-1}$ that indicates the presence of $\mathrm{CuIn}_{3} \mathrm{Se}_{5}$. 
Depth-profile XPS measurements displayed in Figure 3 for an indium selenide layer following $\mathrm{Cu}$-incorporation show that it has a graded composition, with peak copper concentration corresponding to minimum In concentration. The Se concentration decreases within the copper containing region of the layer, relative to its value in copper-free region. This is consistent with the formation of $\mathrm{Cu}_{2-x} \mathrm{Se}$ as it has a higher metal-to-chalcogen ratio than $\operatorname{In}_{2} \mathrm{Se}_{3}$. The depth-profile of the selenized sample is broadly homogenised compared to the un-selenized sample. However, an increase in the concentration of indium throughout the depth of the sample is observed, as is a possible accumulation of $\mathrm{Cu}$ at the back-contact interface. EDX measurements on this selenized sample indicated a Cu:In:Se composition of 21.3:30.9:47.8 at\%. Oxygen impurities were not detected in either sample beyond the first points measured at the surface .
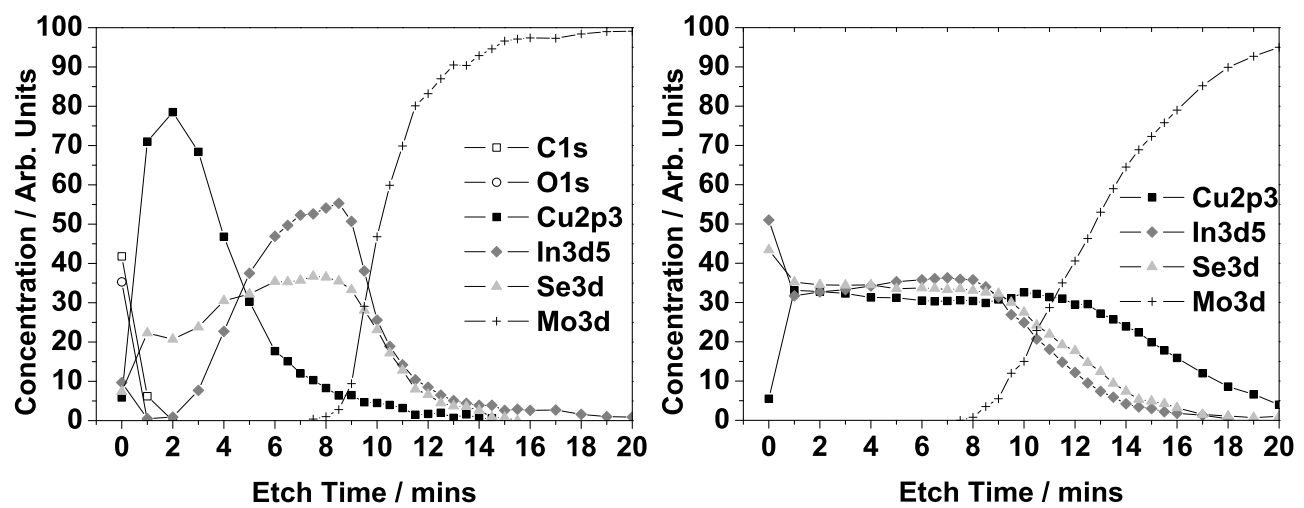

Figure 3: XPS depth-profiles of an indium selenide layer following copper incorporation by ion-exchange (left) and a selenized copper-poor layer (right). Data are not quantitative and indicate only the distribution of the elements throughout the depth of the layers.

The secondary electron images displayed in Figure 4 for indium selenide layers before (left) and after (middle) $\mathrm{Cu}$-incorporation show no significant change in layer morphology, which is consistent with morphology transfer observed in ion-exchange processes [15]. No cracks are observed to form during $\mathrm{Cu}$-incorporation. The secondary electron image displayed in Figure 4 for a selenized layer (right) shows that the layer has re-crystallised with a rough surface. Cross-section secondary electron images displayed in Figure 5 for an indium selenide layer following $\mathrm{Cu}$-incorporation (left) and a selenized Cu-poor layer (right) show that pronounced changes in morphology and grain structure occur during selenization. The selenized copper-poor $\mathrm{CuInSe}_{2}$ layers exhibits a dense microstructure and the rough surface morphology is again apparent. No change in the thickness of the layers after $\mathrm{Cu}$-incorporation could be measured by stylus profilometry, in this case limiting changes in thickness to less than $30 \mathrm{~nm}$. After selenization an average thickness increase of approximately $12 \%$ was measured. 


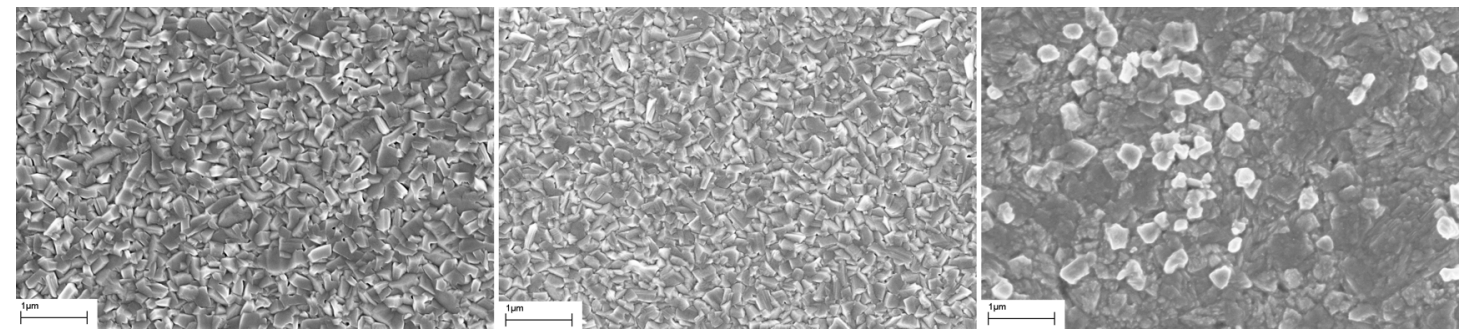

Figure 4: Secondary electron images of as-deposited indium selenide (left), indium selenide following $\mathrm{Cu}$-incorporation by ion-exchange (middle) and a selenized layer

(right).
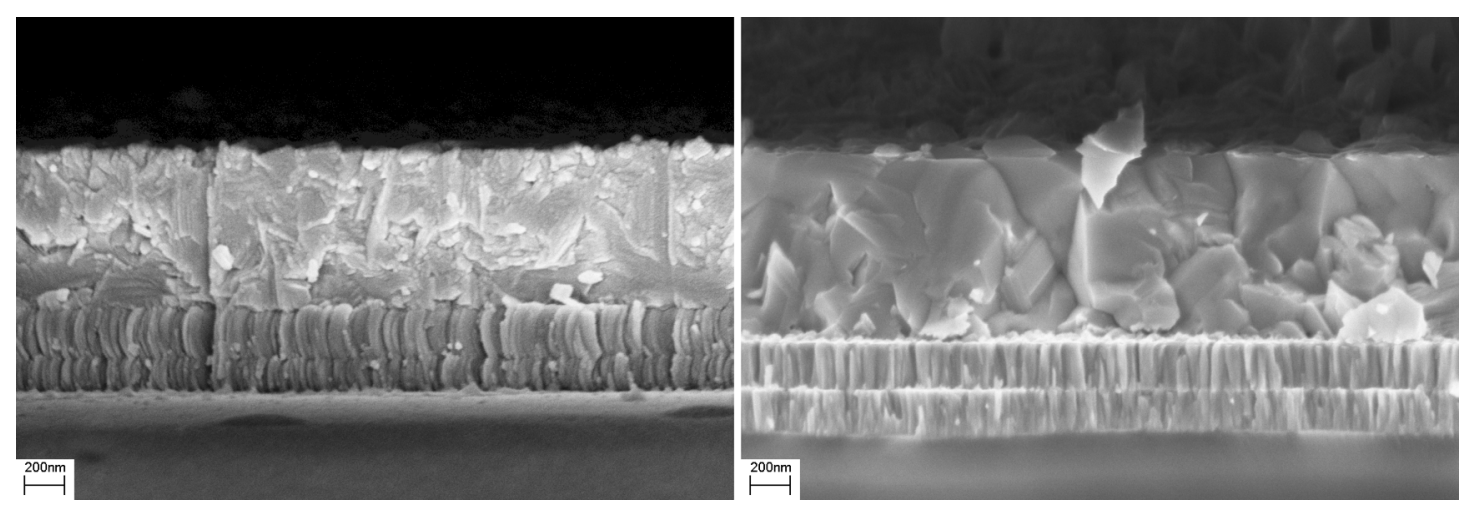

Figure 5: Secondary electron cross-section images of an indium selenide layer following copper incorporation by ion-exchange (left) and a selenized layer (right).

We believe structural properties and crystal structure of indium selenide layers play an important role in the ion exchange process. $\gamma$ - $\mathrm{In}_{2} \mathrm{Se}_{3}$ possesses a defect-wurtzite structure wherein one third of the cation sites are vacant [16]. This crystal structure presents three possible locations for the incorporation of $\mathrm{Cu}$ ions into a $\gamma-\mathrm{In}_{2} \mathrm{Se}_{3}$ layer: as interstitials, on vacant cation sites or on In sites. Incorporation onto an In site requires the removal of the In ion, either to one of the other sites or to the solution. Whilst the precise reaction steps involved in the incorporation of copper into the indium selenide layers remain unclear, from consideration of the data reported here the proposed net mechanism is an ion-exchange reaction according to:

$(6-3 \mathrm{x}) \mathrm{Cu}^{+}{ }_{(\mathrm{aq})}+\mathrm{In}_{2} \mathrm{Se}_{3} \rightarrow 3 \mathrm{Cu}_{2-\mathrm{x}} \mathrm{Se}+2 \operatorname{In}^{3+}{ }_{(\mathrm{aq})}$

This reaction proceeds from the surface of the indium selenide layer and therefore results in a layer of $\beta-\mathrm{Cu}_{2-\mathrm{x}} \mathrm{Se}$ over the $\gamma-\mathrm{In}_{2} \mathrm{Se}_{3}$, with the $\mathrm{Cu}_{2-\mathrm{x}} \mathrm{Se}$ most probably penetrating more rapidly into the $\operatorname{In}_{2} \mathrm{Se}_{3}$ layer along grain boundaries, as has been observed for other ion-exchange reactions involving polycrystalline layers [11]. $\mathrm{Cu}_{2-}$ ${ }_{x}$ Se exhibits high cationic conductivity and high In diffusion coefficients have been specifically observed in $\mathrm{Cu}_{2-x} \mathrm{Se}$ [26], allowing the ion-exchange reaction to continue after the $\mathrm{In}_{2} \mathrm{Se}_{3}$ surface is covered with $\mathrm{Cu}_{2-x} \mathrm{Se}$. Removal of the precursor layer from the hot $\mathrm{CuSO}_{4}$ solution quenches the ion-exchange reaction, hence the $\mathrm{Cu}_{2-\mathrm{x}} \mathrm{Se}$ surface layer should contain a graded concentration of indium ions that were diffusing towards the surface. The diffuse boundary between the copper and indium selenide layers that is observed in the XPS data is attributed in part to these In atoms and in part to interpenetration of the layers along grain boundaries.

$\beta-\mathrm{Cu}_{2-\mathrm{x}} \mathrm{Se}$ and $\gamma-\mathrm{In}_{2} \mathrm{Se}_{3}$ have been observed to react directly to form $\mathrm{CuInSe} \mathrm{Se}_{2}$ at temperatures $>425^{\circ} \mathrm{C}$ in investigations of stacked selenide thin-films and diffusion 
couples [26, 27]. However, the Raman spectra and XRD diffractograms reported here for partially selenized samples indicate a change in the copper selenide phase from $\mathrm{Cu}_{2-\mathrm{x}} \mathrm{Se}$ to $\mathrm{CuSe}$ during selenization of our samples. EDX measurements on $\mathrm{Cu}_{2-\mathrm{x}} \mathrm{Se}$ layers heated to around $250^{\circ} \mathrm{C}$ in our tube furnace and then cooled to room temperature confirmed that the $\mathrm{Cu}$ :Se ratio decreases from 1.7:1 to 1:1. Based on these observations it is concluded that the copper selenide layer formed by ionexchange reacts with elemental Se during heating according to the reaction:

$\mathrm{Cu}_{2-\mathrm{x}} \mathrm{Se}+(1-\mathrm{x}) \mathrm{Se}_{(\text {vapour })} \rightarrow(2-\mathrm{x}) \mathrm{CuSe}$

Therefore, the actual $\mathrm{CuInSe} \mathrm{I}_{2}$ formation reaction that occurs is considered to be:

$2 \mathrm{CuSe}+\mathrm{In}_{2} \mathrm{Se}_{3} \rightarrow 2 \mathrm{CuInSe} \mathrm{Se}_{2}+\mathrm{Se}_{(\text {vaporated })}$

This reaction has been observed directly by high temperature in situ XRD measurements during annealing studies of evaporated bilayers [28]. The incorporation and subsequent loss of selenium during these two reactions should result in first an increase and then a decrease in the volume of the layer. Indeed, stylus profilometry measurements on a sample for which selenization was interrupted at $250^{\circ} \mathrm{C}$ show a thickness increase of approximately $30 \%$ (c.f. $12 \%$ for layers selenized to $575^{\circ} \mathrm{C}$ ). The decrease in thickness that must therefore occur as the selenization proceeds to higher temperatures is identified as a cause of the roughness of the selenized layers [29].

Solar cells processed from selenized precursor layers have exhibited efficiencies of up to $4 \%$ and the J-V curve of such a solar cell is shown in Figure 6 . This cell is typical of solar cells processed during this work in having low open circuit voltage and low shunt resistance. The relatively low device efficiency that has been achieved is considered to arise in large part from the rough morphology of the absorber layers produced so far by this process. Since the morphology of the absorber layer is determined during the selenization process, optimisation of this stage is required to improve the performance of the devices processed from these absorbers. The use of rapid thermal processing (RTP) in place of tube-furnace annealing has been shown to lead to improvements in the morphology of $\mathrm{CuInSe}_{2}$ produced from stacked elemental layers of $\mathrm{Cu}$, In and $\mathrm{Se}[30]$. Similar benefits might be found for the precursors developed in this work, resulting in better quality layers and solar cells.

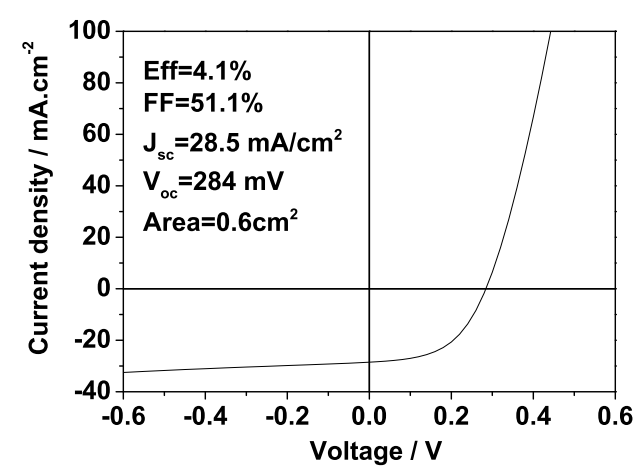

Figure 6: J-V curve for a $\mathrm{CuInSe} \mathrm{I}_{2}$ solar cell processed from a precursor layer produced by ion-exchange incorporation of $\mathrm{Cu}$ into an indium selenide layer. 


\section{Conclusion and prospects}

The chemical incorporation of $\mathrm{Cu}$ into $\mathrm{In}_{2} \mathrm{Se}_{3}$ layers by ion-exchange from aqueous solution is reported. This process results in thin films with a graded compositional depth-profile containing the crystalline phases $\beta-\mathrm{Cu}_{2-x} \mathrm{Se}$ and $\gamma-\mathrm{In}_{2} \mathrm{Se}_{3}$. Annealing these layers in the presence of Se vapour is shown to homogenise the compositional depth-profile of the layers and to form chalcopyrite CuInSe 2 . The ion-exchange solution that was employed was found to be destructive to the exposed areas of the Mo back-contact, however attempts to use alternative back-contact materials resulted in no incorporation of $\mathrm{Cu}$ into the $\mathrm{In}_{2} \mathrm{Se}_{3}$ layers, indicating that Mo activates the $\mathrm{Cu}$-incorporation process.

Solar cells processed from $\mathrm{CuInSe} \mathrm{S}_{2}$ layers produced in this early-stage work showed encouraging characteristics, with efficiencies of up to $4 \%$ under $1 \mathrm{~kW} / \mathrm{m}^{2}$ simulated AM1.5 illumination. However, the devices were characterised by low open circuit voltages and low shunt resistances, attributed to the rough morphology of the layers. Optimization of the selenization process is required to improve the morphology of the absorber layers and this optimization may require the application of rapid thermal processing. The suitability of the absorber layers for use in solar cells could also be increased by incorporation of $\mathrm{Ga}$ into the precursor and work to investigate the behaviour of ( $\mathrm{In}, \mathrm{Ga})_{2} \mathrm{Se}_{3}$ precursor layers during the ion-exchange process is required.

These results demonstrate a potential simple, low-temperature route to the formation of a precursor structure suitable for conversion into $\mathrm{CuInSe}_{2}$ thin-films for solar cell processing. Co-evaporated indium selenide layers were used during this work in the interest of control, however, to fully realise a simple production method for $\mathrm{CuInSe}_{2}-$ based solar cells it is desirable to employ an alternative deposition method. Several non-vacuum methods have been demonstrated in the literature for the deposition of indium selenide and so long as sufficient homogeneity can be achieved there is no reason why they could not be used with the ion-exchange process reported here. Higher rates of $\mathrm{Cu}$ incorporation might be possible with changes to the solution composition, which would be attractive for high-speed processing of layers. Results of further studies on this subject will be reported elsewhere in future.

\section{Acknowledgements}

The authors would like to acknowledge Dr Maxim Ganchev of the Bulgarian Academy of Sciences for a collaboration investigating the growth kinetics of layers, Professor Gauckler of the Swiss Federal Institute of Technology for XRD measurements, Dr Alejandro Perez-Rodriguez of the University of Barcelona for discussion of Raman spectroscopy and a partial support from the Swiss Federal Office of Energy.

\section{References}

1. Contreras M, A., Ramanathan K, AbuShama J, Hasoon F, Young D, L., Egaas B and Noufi R. Diode Characteristics in state-of-the-art $\mathrm{ZnO} / \mathrm{CdS} / \mathrm{Cu}\left(\mathrm{In}_{1-\mathrm{x}} \mathrm{Ga}_{\mathrm{x}}\right) \mathrm{Se}_{2}$ Solar Cells. Progress in Photovoltaics: Research and Applications 2005; 13 : 209-216, DOI: 10.1002/pip.626.

2. Gabor AM, Tuttle JR, Albin DS, Contreras MA, Noufi R and Hermann AM. High-efficiency CuInxGa1-xSe2 solar cells made from (Inx,Ga1-x)2Se3 precursor films. Applied Physics Letters 1994; 65 : 198-200, DOI: 10.1063/1.112670.

3. Zweigart S, Schmid D, Kessler J, Dittrich H and Schock H,W. Studies of the growth mechanism of polycrystalline CuInSe ${ }_{2}$ thin films prepared by a sequential method. Journal of Crystal Growth 1995; 146 : 233-238, DOI: 10.1016/0022-0248(94)00513-3. 
4. Walter T, Braunger D, Dittrich H, Koble C, Herberholz R and Schock HW. Sequential processes for the deposition of polycrystalline $\mathrm{Cu}(\mathrm{In}, \mathrm{Ga})(\mathrm{S}, \mathrm{Se}) 2$ thin films: Growth mechanism and devices. Solar Energy Materials and Solar Cells 1996; 41-42 : 355-372, DOI :10.1016/0927-0248(95)00103-4.

5. Nishiwaki S, Satoh T, Hayashi S, Hashimoto Y, Negami T and Wada T. Preparation of $\mathrm{Cu}(\mathrm{In}, \mathrm{Ga}) \mathrm{Se} 2$ Thin Films from In - Ga - Se Precursors for High-Efficiency Solar Cells. Journal of Materials Research 1999; 14(12) : 4514-4520, DOI: 10.1557/JMR.1999.0613.

6. Amory C, Bernède E, Halgand $\mathrm{E}$ and Marsillac $\mathrm{S}$. $\mathrm{Cu}(\mathrm{In}, \mathrm{Ga}) \mathrm{Se} 2$ Films Obtained from $\gamma$ - $\mathrm{In}_{2} \mathrm{Se}_{3}$ Thin Film. Thin Solid Films 2003; 431-432 : 22-25, DOI: 10.1016/S0040-6090(03)00237-2.

7. Ashida A, Hachiuma Y, Yamamoto N, Ito T and Cho Y. CuInSe ${ }_{2}$ thin films prepared by quasi-flash evaporation of $\mathrm{In}_{2} \mathrm{Se}_{3}$ and $\mathrm{Cu}_{2} \mathrm{Se}$. Journal of Materials Science Letters 1994; 13(16) : 1181-1184, DOI: 10.1007/BF00241004.

8. Kessler J, Schmid D, Zweigart S, Dittrich H and Schock HW. CuInSe ${ }_{2}$ film formation from sequential depositions of In(Se):Cu:Se. 12th European Photovoltaic Solar Energy Conference Amsterdam 1994; 648652.

9. Park S, C., Lee D, Y., Ahn B, T., Yoon K, H. and Song J. Fabrication of CuInSe2 films and solar cells by the sequential evaporation of In2Se3 and Cu2Se binary compounds. Solar Energy Materials and Solar Cells 2001; 69 : 99-105, DOI:10.1016/S0927-0248(00)00382-2.

10. Nishiwaki S, Satoh T, Hayashi S, Hashimoto Y, Shimakawa S, Negami T and Wada T. Preparation of $\mathrm{Cu}(\mathrm{In}, \mathrm{Ga}) \mathrm{Se}_{2}$ thin films from Cu-Se $\mathrm{In}$-Ga-Se precursors for high-efficiency solar cells. Solar Energy Materials and Solar Cells 2001; 67 : 217-223, DOI:10.1016/S0927-0248(00)00284-1.

11. Pfisterer $F$. The wet-topotaxial process of junction formation and surface treatments of $\mathrm{Cu}_{2} \mathrm{~S}-\mathrm{CdS}$ thin-film solar cells. Thin Solid Films 2003; 431-432 : 470-476, DOI: 10.1016/S0040-6090(03)00166-4.

12. Ali A, Shah NA, Aqili AKS and Maqsood A. Investigation of Cu-containing low resistivity CdTe thin films deposited by the two-source evaporation technique. Semiconductor Science and Technology 2006; 21(9): 1296-1302, DOI: 10.1088/0268-1242/21/9/014.

13. Wada T, Hayashi S, Hashimoto Y, Nishiwaki S, Sato T, Negami T and Nishitani M. High efficiency $\mathrm{Cu}(\mathrm{In}, \mathrm{Ga}) \mathrm{Se}_{2}$ (CIGS) solar cells with improved CIGS surface. $2^{\text {nd }}$ World Conference and Exhibition on Photovoltaic Solar Energy Conversion Vienna, Austria 1998; 403-408.

14. Moller J, Fischer C-, Muffler H-, Konenkamp R, Kaiser I, Kelch C and Lux-Steiner MC. A novel deposition technique for compound semiconductors on highly porous substrates: ILGAR. Thin Solid Films 2000; 361-362 : 113-117, DOI: 10.1016/S0040-6090(99)00797-X.

15. Dloczik L, Lux-Steiner MC and Koenenkamp R. Study on the preparation of structured $\mathrm{CuInS}_{2}$ films by ion exchange processes. Thin Solid Films 2003; 431-432 : 131-134, DOI: 10.1016/S0040-6090(03)00195-0.

16. Yudasaka M, Matsuoka T and Nakanishi K. Indium Selenide Film Formation by the Double-Source Evaporation of Indium and Selenium. Thin Solid Films 1987; 146 : 65-73, DOI: 10.1016/00406090(87)90340-3.

17. Herrero J and Ortega J. Electrochemical synthesis of photoactive $\operatorname{In}_{2} \mathrm{Se}_{3}$ thin films. Solar Energy Materials 1987; 16 : 477-485, DOI: 10.1016/0165-1633(87)90049-9.

18. Massaccesi S, Sanchez S and Vedel J. Electrodeposition of indium selenide $\operatorname{In}_{2} \mathrm{Se}_{3}$. Journal of Electroanalytical Chemistry 1996; 412 : 95-101, DOI:10.1016/0022-0728(96)04604-9.

19. Pathan H, M., Kulkarni S, S., Mane R, S. and Lokhande C, D. Preparation and characterization of indium selenide thin films from a chemical route. Materials Chemistry and Physics 2005; 93 : 16-20, DOI: 10.1016/j.matchemphys.2005.01.063.

20. Bouzouita H, Bouguila N, Duchemin S, Fiechter S and Dhouib A. Preparation and characterization of In2Se3 thin films. Renewable Energy 2002; 25 : 131-138, DOI: 10.1016/S0960-1481(00)00193-2.

21. Emziane $\mathrm{M}$ and Le Ny R. Crystallization of $\operatorname{In}_{2} \mathrm{Se}_{3}$ semiconductor thin films by post-deposition heat treatment. Thickness and substrate effects. Journal of Physics D: Applied Physics 1999; 32(12) : 1319-1328, DOI:10.1088/0022-3727/32/12/307.

22. Izquierdo-Roca V, Perez-Rodriguez A, Romano-Rodriguez A, Morante J,R., Alvarez-Garcia J and CalvoBarrio L. Raman microprobe characterization of electrodeposited S-rich $\mathrm{CuIn}(\mathrm{S}, \mathrm{Se})_{2}$ for photovoltaic applications: Microstructural analysis. Journal of Applied Physics 2007; 101 : 103517-1-103517-8, DOI: 10.1063/1.2734103.

23. Neumann H. Lattice vibrational, thermal and mechanical properties of CuInSe $\mathrm{C}_{2}$. Solar Cells 1986; 16: 399 418, DOI: $10.1016 / 0379-6787(86) 90100-6$.

24. Tiwari A, N. and Blunier S. Characterisation of heteroepitaxial $\mathrm{CuIn}_{3} \mathrm{Se}_{5}$ and $\mathrm{CuInSe}_{2}$ layers on Si Substrates. Applied Physics Letters 1994; 65 : 3347-3349, DOI: 10.1063/1.112387.

25. Ishi M, Shibata K and Nozaki H. Anion distributions and phase transitions in $\mathrm{CuS}_{1-\mathrm{x}} \mathrm{Se}_{\mathrm{x}}(\mathrm{x}=0-1)$ studied by Raman spectroscopy. Journal of Solid State Chemistry 1993; 105 : 504-511, DOI: 10.1006/jssc.1993.1242.

26. Park J,S., Dong Z, Kim S and Perepezko J,H. CuInSe 2 phase formation during $\mathrm{Cu}_{2} \mathrm{Se}_{\mathrm{In}} \mathrm{Se}_{3}$ interdiffusion reaction. Journal of Applied Physics 2000; 87 : 3683-3690, DOI: 10.1063/1.372400.

27. Hergert F, Hock R, Weber A, Purwins M, Palm J and Probst V. In-situ Investigation of the Formation of $\mathrm{Cu}(\mathrm{In}, \mathrm{Ga}) \mathrm{Se} 2$ from Selenized Metallic Precursors by X-ray Diffraction - The Impact of Gallium, Sodium and Selenium Excess. Journal of Physics and Chemistry of Solids 2005; 66 : 1903-1907, DOI: 10.1016/j.jpcs.2005.09.025.

28. Kim WK, Kim S, Payzant EA, Speakman SA, Yoon S, Kaczynski RM, Acher RD, Anderson TJ, Crisalle OD, Li SS and Craciun V. Reaction Kinetics of a-CuInSe2 Formation from an In2Se3 / CuSe Bilayer Precursor Film. Journal of Physics and Chemistry of Solids 2005; 66 : 1915, DOI: 10.1016/j.jpcs.2005.09.074. 
29. Guillén C and Herrero J. Semiconductor CuInSe2 Formation by Close-Spaced Selenization Processes in Vacuum. Vacuum 2002; 67 : 659, DOI:10.1016/S0042-207X(02)00258-0.

30. Karg F, Probst V, Harms H, Rimmasch J, Riedl W, Kotschy J, Holz. J, Treichler R, Eibl O, Mitwalsky A and Kiendl A. Novel rapid-thermal-processing for CIS thin-film solar cells. 23rd IEEE Photovoltaic Specialists Conference 1993; 441-446, DOI: 10.1109/PVSC.1993.347141. 